\title{
Practical use of the vaccination indicator in poultry farming
}

\author{
Nadezhda Momot $^{1 *}$, Yulia Kolina ${ }^{1}$, Igor Kamliya ${ }^{1}$, Alexey Trebukhov ${ }^{2}$ and Elena \\ Shaganova $^{2}$ \\ ${ }^{1}$ Primorye State Agricultural Academy, 692510, Ussuriysk, Russian Federation \\ ${ }^{2}$ Altai State Agricultural University, 656049, Barnaul, Russian Federation
}

\begin{abstract}
The article presents data related to the course of the vaccination experiment in the experimental group using the Vacci Blue preparation. At the same time, its good solubility in water without formation of any sediment is noted, as well as a positive effect on the quality control of young poultry vaccination in production conditions, which makes it possible for poultry farms to monitor the progress of preventive measures. The Vacci Blue preparation can be used as a vaccination indicator in poultry farming.
\end{abstract}

\section{Introduction}

Poultry farming is a promising direction of the agro-industrial complex, associated with high rates of development. The high profitability of this livestock sector is associated both with a wide range of manufactured products, primary and secondary raw materials, and with relatively low resource costs (feed, means, labor) per product unit [1,2]. Developing poultry farming proportionally leads to an increase in the volume of both products and raw materials. The meat and egg directions of poultry farming are suppliers of dietary meat and egg products, which are necessary for human life, since they contain high-grade protein, various biologically active substances $[1,3]$. Down and feather are used by the processing industry; poultry farming is a constant supplier of raw materials for the pharmaceutical, chemical, and microbiological industries.

Industrial poultry farming provides the population with the diet protein part of the animal origin by $30 \%$. Poultry meat has a high nutritional, biological value, a full set of amino acids, lipids rich in polyunsaturated fatty acids. Poultry meat contains: water - 50$70 \%$; proteins - 16-22\%; fats - 16-45\%; minerals and vitamins, a small amount of carbohydrates. Chicken eggs contain all the nutrients and biologically active substances necessary for a person, which are in the optimal ratio: $12-15 \%$ of protein, $11-15 \%$ of fat, $1 \%$ of carbohydrates, $74 \%$ of water and about $1 \%$ of inorganic substances.

The poultry population in industrial poultry farming is concentrated in limited territories, while using cage or floor keeping of poultry. The level of mechanization and automation of production processes contributes to the intensification of poultry farming. For farm poultry feeding, dry feed is used balanced in terms of nutrition to obtain high

*Corresponding author: momot18@mail.ru 
productivity at optimal cost. The highest quality meat is obtained from broilers - hybrid meat young animals of all types of poultry with specialized cultivation. At present time, active breeding work is being carried out with chicken crosses, providing the phenomenon of heterosis in the hybrid - broiler.

Timely implementation of therapeutic and preventive measures allows to ensure the receipt of healthy livestock and, as a result, high-quality livestock and poultry products, regardless of the forms of ownership of enterprises [4,5,6]. The processes of changing the ecology of pathogens and diseases, the emergence of new infectious diseases require today a more thorough scientific analysis and generalization, the early development of prevention and control measures. The registration of infectious diseases in the country, such as mycoplasmosis, coccidiosis, colibacteriosis, Newcastle disease, infectious bronchitis, Marek's disease, etc. indicates a weakening of veterinary control and specific measures for the prevention of these diseases. Strict compliance with veterinary and sanitary rules during egg incubation, during the rearing of young animals and the maintenance of adult poultry guarantees the achievement of high production indicators.

For the prevention of poultry infectious diseases, various vaccines are used, which have both certain advantages and disadvantages. At present, monovalent and polyvalent vaccines are used. Often, polyvalent vaccines are much more effective than monovaccines, especially against virulent strains that become dominant in areas of intensive poultry farming. The vaccines used should be selected considering the spread of infectious agent and poultry breed. The effectiveness and rationality of the use of existing vaccines is associated with the timeliness of their application, without waiting for the appearance of new pathogen modifications [7-10].

Animal epidemic countermeasures include both general and specific prevention. In the fight against each specific infection, it is always necessary to find the main link, when exposed to which it is possible to achieve complete recovery of the economy and disease prevention in the shortest possible time and with the least losses.

Despite the fact that various technological schemes of poultry keeping have been developed at the moment, the problem of prevention and elimination of poultry infectious diseases remains relevant. The use of antibiotics, viral and bacterial infections, as well as stress factors have a negative impact on the development of the immune system of birds. $[10,11]$. The immune system impairment leads to acquired immunodeficiency. Immunoprophylaxis plays a leading role in the complex of animal epidemic countermeasures aimed at eliminating infectious diseases of animals and poultry, and in particular Newcastle disease and infectious bronchitis of chickens.

The purpose of this study is to identify the practical feasibility of using Vacci Blue in poultry farming.

Research tasks:

1. to study the technical possibilities of using the vaccination indicator;

2. practical use of Vacci Blue in preventive measures;

3. analysis of the results obtained during practical use.

\section{Material and methods}

To carry out routine vaccination with the use of the La-Sota vaccine, experimental studies were conducted in the conditions of the poultry farm Agroptitsa LLC, located on the territory of the Primorsky Krai. The poultry farm is safe for bird infectious diseases. Specific prevention is carried out on the basis of vaccination schemes approved at this poultry farm in accordance with the established procedure, considering the epizootic situation. When carrying out vaccination, a dye and a water stabilizer for vaccination with Vacci Blue were used. 
The object of the study was broiler chickens of the Ross308 breed, kept at the poultry farm Agroptitsa LLC.

During the experiment two groups were formed on one-day broiler chickens $(n=100)$, selected according to the principle of analogues: control $(n=50)$ and experimental $(n=50)$. The conditions of keeping in all groups were similar: the chickens were placed on the floor throughout the entire growing period.

During the activities in the control group, the La-Sota vaccine was used by the method of drinking with water (Table 1).

Table 1. The scheme of Newcastle disease prevention in the control group.

\begin{tabular}{|c|l|l|l|}
\hline No. & Solutions, preparations & Frequency of administration & Method of administration \\
\hline 1 & La-Sota & In the first day of life. Once & Alimentary (bottle-feeding) \\
\hline
\end{tabular}

In the experimental group, broiler chickens were treated with the same vaccine (La-Sota) for the prevention of Newcastle disease, but in combination with a dye and a stabilizer Vacci Blue by bottle-feeding with water (Table 2).

Table 2. The scheme of Newcastle disease prevention in the experimental group

\begin{tabular}{|c|l|l|l|}
\hline No. & Solutions, preparations & Frequency of administration & Method of administration \\
\hline 1 & La-Sota & In the first day of life & Alimentary (bottle-feeding) \\
\hline 2 & Vacci Blue & In the first day of life & Alimentary (bottle-feeding) \\
\hline
\end{tabular}

The water stabilizer and vaccination indicator in poultry farming contains food dye E133, sodium thiosulfate (chlorine deactivator), sodium hydrocarbonate and Trilon B.

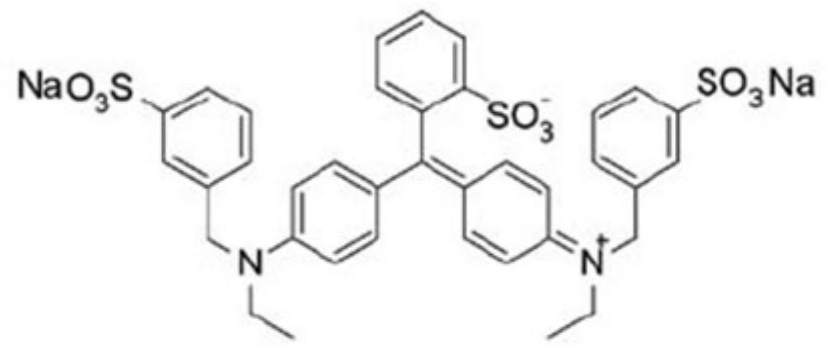

Fig.1. The dye is brilliant blue FCF.

Synthetic dye E 133 is approved for use in the food industry in the following territories (Table 3). 
Table 3. Synthetic dye E 133 and its application possibilities

\begin{tabular}{|c|c|c|c|c|c|}
\hline Synthetic dye & $\begin{array}{c}\text { E } \\
\text { number }\end{array}$ & EAEU, RB & $\begin{array}{c}\text { European } \\
\text { Union }\end{array}$ & $\begin{array}{c}\text { Codex } \\
\text { Alimentarius }\end{array}$ & USA \\
\hline $\begin{array}{c}\text { Brilliant Blue } \\
\text { FCF }\end{array}$ & E 133 & + & + & + & + \\
\hline
\end{tabular}

Note: "+" is allowed for use; "-" not allowed for use; EAEU - the Eurasian Economic Union; RB - the Republic of Belarus; Codex Alimentarius - set of international food standards

Sodium thiosulfate $\left(\mathrm{Na}_{2} \mathrm{~S}_{2} \mathrm{O}_{3}\right)$ is a strong reducing agent, it is oxidized by chlorine to sulfates or sulfuric acid, captures and retains chlorine, manifesting the functions of a chlorine deactivator.

Sodium hydrocarbonate $\left(\mathrm{NaHCO}_{3}\right)$ exhibits buffering properties, since the $\mathrm{pH}$ of the aqueous solution does not change significantly.

The disodium salt of ethylenediaminetetraacetic acid (Trilon B) is a coagulant ion that gives solubility to insoluble salts of some metals.

\section{Results and discussion}

In the control group, the vaccination of young poultry was carried out by bottle-feeding method in the doses provided for in the instructions for the use of this vaccine. After the vaccination, we paid attention to the post-vaccination state of the poultry and the general clinical picture after its application. After its use, the general condition of the poultry corresponded to a satisfactory condition and no fatal outcomes were observed during clinical observations.

In the experimental group, vaccination of broiler chickens was carried out by bottlefeeding method with the use of the vaccine stabilizer Vacci Blue, which was used in the following dose: $10 \mathrm{~g}$ per 100 liters of water. The indicator dye has the ability to dissolve well in cold water, while it does not form any sediment in the water. Based on these properties of the Vacci Blue reagent, according to our data, it was ready for use within 3-5 minutes after preparation.

After vaccination, attention was drawn to the clinical condition of the vaccinated bird, which we recorded as satisfactory. In addition, a visual analysis was made for the color of the tongue and beak of young poultry, which allowed for an individual approach to the course of the activities carried out. Coloring them in blue indicates the quality of vaccination of each bird, thereby facilitating the monitoring of the course of vaccination. There were no fatal outcomes in broiler chickens.

\section{Conclusions}

During the vaccination experiment in the experimental group using the Vacci Blue preparation at a dose of $10 \mathrm{~g}$ per 100 liters of water, its good solubility in water is noted without the formation of any sediment. Moreover, there is a positive impact on the quality control of the vaccination of young poultry in production conditions, which allows poultry farms to monitor the progress of preventive measures. The Vacci Blue preparation can be used as a vaccination indicator in poultry farming. 


\section{References}

1. Yu.A. Kolina, N.V. Momot, I.L. Kamliya, To the prevention of infectious diseases of young chickens in the conditions of a private farmstead, The role of agrarian science in the development of forestry and agriculture of the Far East: Materials of the IV National (All-Russian) Scientific and Practical Conference, 312-315 (Ussuriysk, Primorye State Agricultural Academy, 2020)

2. D.V. Comin, I.I. Borodin, Review of methods of conducting physiological tests of poultry on the example of quails, Innovations of young people - development of agriculture: Materials of the 56th All-Russian Scientific Student Conference, 40-43 (Ussuriysk, Primorye State Agricultural Academy, 2020)

3. E.I. Polyanskikh, L.L. Belysheva, T.A. Fedorova [et al.], Chemical safety 3 (1), 166181 (2019) DOI 10.25514/CHS.2019.1.15013.

4. N.V. Momot, Yu.A. Kolina, I.L. Kamlia, S.V. Terebova, Hippology and veterinary medicine 1 (39), 142-146 (2021)

5. N.V. Momot, Yu.A. Kolina, Veterinary and sanitary assessment of the quality of poultry meat products, Actual issues of food production development: technologies, quality, ecology, equipment, management and marketing: Materials of the IV National (All-Russian) Scientific and Practical Conference, 45-48 (Ussuriysk, Primorye State Agricultural Academy, 2020)

6. A. Trebukhov, N. Momot, Y. Kolina, I. Kamliya, E3S Web of Conferences, (2021) DOI 10.1051/e3sconf/202125409007

7. V.A. Levkina, I.N. Gromov, L. N. Gromova, Animal husbandry and veterinary medicine 1(40), 69-73 (2021)

8. N.V. Pimenov, Virosalm vaccine - a new biological product for the specific prevention of salmonellosis and Newcastle disease of birds, Innovative trends in the development of Russian science: Materials of the IV International (correspondence) Scientific and Practical Conference of Young Scientists, 139-142 (Krasnoyarsk: Krasnoyarsk State Agrarian University, 2011)

9. M.V. Podolskaya, S.M. Milyukov, The first domestic experience of the use of the oncolytic virus of the Newcastle disease in the complex treatment of malignant neoplasms, Actual issues of experimental and clinical oncology. Collection of materials of the All-Russian Conference of Young Oncologists dedicated to the memory of RAMS Academician N.V. Vasilyev 139-142 (2016)

10. A.T. Kushnir, I.A. Bureev, Yu.O. Selyaninov [et al.], Prevention of infectious diseases of animals with aerosols of chemical and biological preparations, 192 (St. Petersburg, Publishing House "Lan", 2016) ISBN 9785811420469

11. Yu.O. Stoyanskaya, N.V. Momot, Rehabilitation of birds of prey, Innovations of young people - development of agriculture: Materials of the 56th All-Russian Scientific Student Conference, 116-119 (Ussuriysk, Primorye State Agricultural Academy, 2020) 